\title{
Review of heat and water movement in field soils
}

\author{
M.B. Parlange ${ }^{\mathrm{a},{ }^{*}}$, A.T. Cahill ${ }^{\mathrm{a}}$, D.R. Nielsen ${ }^{\mathrm{b}}$, J.W. Hopmans ${ }^{\mathrm{b}}$, O. Wendroth ${ }^{\mathrm{c}}$ \\ a Department of Geography and Environmental Engineering, Ames Hall, Johns Hopkins University, Baltimore, MD 21218, USA \\ ${ }^{\mathrm{b}}$ Hydrology Program, Department of Land, Air and Water Resources, University of California, Davis, CA 95616, USA \\ ${ }^{\mathrm{c}}$ Institute for soil research at the Agrolandscape and Land Use Research Center, 15374 Muencheberg, Germany
}

\begin{abstract}
Coupled heat and water transport in soils has enjoyed extensive focus in soil physics and hydrology and yet, until recently, there has never been a satisfactory comparison of water vapor fluxes measured in the field with theory. At least two factors have led to this, first, most of the experimental work has been laboratory oriented with steady state boundary conditions imposed and second, there have been relatively few field experiments to test the existing theory. In this paper we review a new theoretical development which explains field observations of water vapor movement. The diurnal warming at the land surface leads to an expansion and contraction of the soil air as it warms and cools resulting in a convective (or "advective") transport of water vapor. This mechanism has important consequences for the transport of any vapor in the soil air near the landatmosphere interface. (C) 1998 Published by Elsevier Science B.V. All rights reserved.
\end{abstract}

Keywords: Water vapor; Coupled heat and water movement; Convective transport

\section{Introduction}

Coupled heat and water movement in the unsaturated soil near the land atmosphere interface, the vadose zone, plays a central role in hydrology. The soil moisture near the land surface controls the transfer of precipitation into quick storm runoff and infiltration and the partitioning of available energy into latent and sensible heat fluxes into the atmosphere. In addition, biological processes such as soil microbial activity and plant growth depend on the moisture and temperature status in the vadose zone.

There has never been a satisfactory comparison of the theory (Philip and de Vries, 1957) for water vapor movement in soils with short term field observations

\footnotetext{
*Corresponding author.
}

(e.g. Rose, 1968a, b; Jackson et al., 1974; Cass et al., 1984; Monji et al., 1990; Cahill and Parlange, 1998). The observed vapor flow is one order of magnitude greater than what the theory predicts. To date the approach in soil and agricultural science has been to describe this unexplained "enhanced" vapor flow by using tuning factors to increase the predicted vapor flow by one order of magnitude such that it matches the observed vapor flow.

This paper reviews a new transport theory for coupled heat and water movement in soils to explain the vapor flow obtained from field observations (Cahill and Parlange, 1998; Cahill et al., 1998). The mechanism responsible for the large vapor flux is convective transport driven by the diurnal heating and cooling of the soil surface and the corresponding thermal expansion and contraction of the soil air. 
It is well known that the movement of moisture and heat in the soil are linked (e.g. Boucoyous, 1915). One of the first field studies of the coupled effects of soil heat and moisture transport was by Rose (1968a, b). Rose discovered that the amount of water transported through a soil layer as vapor was on the same order of magnitude as the increase or decrease of the volumetric moisture content in that layer. Jackson in Arizona (Jackson, 1973; Jackson et al., 1974) found that water vapor fluxes were of the same order as Rose (1968b). Monji et al. (1990) in Japan also found similar values of water vapor transport for field experiments. Westcot and Wierenga (1974) found that heat transported by vapor flux accounted for $40-60 \%$ of total heat flux in the top $2 \mathrm{~cm}$ of the soil. More recently, Cahill and Parlange (1998) examined the transport of water in a bare field soil (Yolo silt loam) using subsurface measurements of soil temperature and volumetric moisture content. A significant amount $(40-60 \%)$ of the heat flux was due to vapor transport and the contribution of the water vapor flux to the total moisture flux was also significant (10-30\%). Some of these data are used here to demonstrate the new convective theory.

\section{Theory}

The heat flux density in soil is given by

$$
q_{\mathrm{h}}=-\lambda \nabla T+\rho L q_{\mathrm{v}}+c_{\mathrm{pl}} \rho\left(T-T_{0}\right) q_{\mathrm{m}}
$$

where $q_{\mathrm{h}}$ is the heat flux density $\left[\mathrm{W} / \mathrm{m}^{2}\right], \lambda$ is the thermal conductivity $[\mathrm{W} / \mathrm{mK}], T$ is the temperature $[\mathrm{K}], \rho$ is the density of water $\left[\mathrm{kg} / \mathrm{m}^{3}\right], L$ is the latent heat of vaporization $\left[\sim 2.45 \times 10^{6} \mathrm{~J} / \mathrm{kg}\right], c_{\mathrm{pl}}$ is the specific heat of liquid water $[4182 \mathrm{~J} / \mathrm{kgK}], T_{0}$ is an arbitrary reference temperature $[\mathrm{K}]$ which is taken in the example presented below to be $25^{\circ} \mathrm{C}, q_{\mathrm{v}}$ is the water vapor flux and $q_{\mathrm{m}}$ is the total moisture flux [both in units of $\mathrm{m} / \mathrm{s}$ ], which is simply equal to the sum of the vapor flux $q_{\mathrm{v}}$ and the liquid water flux $q_{1}$ (de Vries, 1958). The driving terms on the right-hand side of (1) includes a Fourier conduction term and terms which express heat transported by mass transfer.

Soil thermal conductivity is a function of the geometrical arrangement of the phases in the soil matrix. Estimation of the thermal conductivity of soils with varying moisture content has often been done with the method proposed by de Vries (1963). This relationship is

$$
\lambda=\frac{\sum_{i=0}^{n} k_{i} X_{i} \lambda_{i}}{\sum_{i=0}^{n} k_{i} X_{i}}
$$

where $X_{i}$ is the volume fraction of the $i$-th phase (quartz, other solids, organics, water or air), and $\lambda_{i}$ is the thermal conductivity of the $i$-th phase. The subscript 0 is reserved for the continuous phase, which is considered to be water for a "wet" soil, and air for a "dry" one. The value of $k_{0}$ is defined to be 1 , and the value of $k_{i}$ for $i$ greater than 0 is given by

$$
k_{i}=\frac{1}{3} \sum_{j=1}^{3}\left[1+\left(\frac{\lambda_{i}}{\lambda_{0}}-1\right) g_{j}\right]^{-1}
$$

where $g_{j}$ is a shape factor, with $g_{1}+g_{2}+g_{3}=1$. Wierenga et al. (1969) derived soil-specific formulae for the shape factors $g_{j}$ for the de Vries formula for thermal conductivity for the Yolo silt loam which are used here.

The total moisture flux is

$$
q_{\mathrm{m}}=q_{1}+q_{\mathrm{v}}
$$

where the liquid flux is

$$
q_{1}=-D_{\theta 1} \nabla \theta-D_{\mathrm{Tl}} \nabla T-K
$$

and $\theta$ is the volumetric moisture content, $D_{\theta 1}$ is the isothermal liquid diffusivity $\left[\mathrm{m}_{2} / \mathrm{s}\right], D_{\mathrm{T} 1}$ is the thermal liquid diffusivity $\left[\mathrm{m}^{2} / \mathrm{sK}\right]$ and $K$ is the hydraulic conductivity $[\mathrm{m} / \mathrm{s}]$ (Philip and de Vries, 1957). The isothermal liquid diffusivity is

$$
D_{\theta 1}=K \frac{\partial \psi}{\partial \theta}
$$

where $\psi$ is the matric potential [m]. The thermal liquid diffusivity arises from the flux due to changes in surface tension due to change in temperature:

$$
D_{\mathrm{Tl}}=K \gamma \psi
$$

where $\gamma$ is the relative change in surface tension $\sigma$ with respect to temperature:

$$
\gamma=\frac{1}{\sigma} \frac{\mathrm{d} \sigma}{\mathrm{d} T}
$$

The relation of $\psi$ and $K$ to $\theta$ is defined with a van Genuchten (1980) equation for $\psi$ and the Brooks and Corey relationship for $K$. This combination was chosen based on the analysis of Fuentes et al. (1992). The 
relative change in surface tension with respect to temperature is not constant (Hopmans and Dane, 1986), but the variation is small and the value of $-2.09 \times 10^{-3 \circ} \mathrm{C}^{-1}$ given in Philip and de Vries (1957) is used here.

The theory of Philip and de Vries (1957) for vapor flux uses the thermodynamic relationship between water vapor density $\rho_{\mathrm{v}}$, matric potential and temperature (Edlefsen and Anderson, 1943)

$$
\rho_{\mathrm{v}}=\rho_{\mathrm{vs}} \exp \left(\frac{\psi g}{R T}\right)
$$

where $\rho_{\mathrm{vs}}$ is the saturated water vapor density at a given temperature, $g$ is the acceleration due to gravity, and $R$ is the gas constant. This allows the vapor flux to be broken into an isothermal part driven by the moisture content gradient and a thermal part driven by the temperature gradient

$$
q_{\mathrm{v}}=-D_{\theta \mathrm{v}} \nabla \theta-D_{\mathrm{Tv}} \nabla T
$$

where $D_{\theta \mathrm{v}}$ and $D_{\mathrm{Tv}}$ are the appropriate diffusivities. The Philip and de Vries model for the vapor diffusion coefficients are

$$
D_{\theta \mathrm{v}}=\frac{\alpha a D_{\mathrm{a}} \nu g \rho_{\mathrm{v}}}{R T \rho_{l}} \frac{\partial \psi}{\partial \theta} ; D_{\mathrm{Tv}}=\eta \alpha a D_{\mathrm{a}} \nu \frac{\mathrm{d} \rho_{\mathrm{vs}}}{\mathrm{d} T}
$$

where $a$ is the volumetric air content, $\alpha$ is a tortuosity factor, $D_{\mathrm{a}}$ is the diffusivity of water vapor in still air and $\nu$ is a mass-flow factor taken to be 1 . The term $\eta$ is a factor that accounts for additional pore space available for the water vapor to move through, due to the ability of water vapor to condense on one side of a water-saturated pore and evaporate on the other. In addition it accounts for the enhanced temperature gradient in individual pores relative to a bulk temperature gradient. Various models for the enhancement factor have been developed (e.g. Philip and de Vries, 1957; Jury and Letey, 1979; Cary, 1979).

Milly (1982) rewrote (10) using the matric potential as the independent variable instead of $\theta$. The use of matric potential as the independent variable removes some of the difficulties which arise if the soil profile is not homogeneous (Scanlon and Milly, 1994). Horton's group (Nassar and Horton, 1992 and Nassar et al., 1992) have had success with the general theory based on laboratory experiments where they impose diffusive conditions with no diurnal forcing of the surface boundary condition. The failure of current theory to explain water vapor fluxes in field soils has represented a large gap in our knowledge of the vadose zone energy and water balance.

\section{Experiments}

Some field experiments have been carried out at the Davis, California field site (Yolo silt loam). The data used for estimation of the diffusivities were collected at the Campbell Tract research field of the University of California, Davis. Platinum resistance temperature detectors (PRTD) were installed at five depths: 2, 4, 7 , 10 , and $15 \mathrm{~cm}$; next to them time domain reflectometry (TDR) probes were inserted horizontally into the soil. These TDR probes were the three-prong $30 \mathrm{~cm}$ type discussed by Heimovaara (1993). The TDR waveforms and soil temperatures were measured every twenty minutes, and analyzed using the calibration presented by Dasberg and Hopmans (1992).

We made use of Eqs. (1) and (4) independently to obtain two different time series of $q_{\mathrm{v}}$ (Cahill and Parlange, 1998). The measured values of temperature and moisture content were used to compute the vapor flux from the two transport equations which yielded essentially identical results (Cahill and Parlange, 1998).

The equation for conservation of energy is

$$
C \frac{\partial T}{\partial t}=-\nabla \cdot q_{\mathrm{h}}
$$

where $C$ is the heat capacity of the soil and $t$ is time. This equation can be integrated over the layer of interest,

$$
\begin{aligned}
\int_{7 \mathrm{~cm}}^{10 \mathrm{~cm}} C \frac{\partial T}{\partial t} \mathrm{~d} z= & \left(-\lambda \frac{\partial T}{\partial z}\right)_{10}-\left(-\lambda \frac{\partial T}{\partial z}\right)_{7} \\
& +\left(\rho\left(L+C_{\mathrm{pl}}\left(T-T_{0}\right)\right) q_{\mathrm{v}}\right)_{10} \\
& -\left(\rho\left(L+C_{\mathrm{pl}}\left(T-T_{0}\right)\right) q_{\mathrm{v}}\right)_{7} \\
& +\left(\rho C_{\mathrm{pl}}\left(T-T_{0}\right) q_{1}\right)_{10} \\
& -\left(\rho C_{\mathrm{pl}}\left(T-T_{0}\right) q_{1}\right)_{7}
\end{aligned}
$$

where the left hand side represents the net change in heat energy and the three terms on the right hand side represent change due to conduction, change due to vapor flux and change due to liquid flux, respectively. The derivatives of $T$ were approximated by finite 
differences. A similar analysis was done for the mass flux. The mass balance equation can be integrated over the soil layer

$$
\int_{7 \mathrm{~cm}}^{10 \mathrm{~cm}} \frac{\partial \theta}{\partial t} \mathrm{~d} z=\left[q_{1_{10}}-q_{1_{7}}\right]+\left[q_{\mathrm{v}_{10}}-q_{\mathrm{v}_{7}}\right]
$$

where the left hand side is the net change in moisture content and the first term on the right hand side is the change due to liquid flux and the second is the change due to vapor flux. Since the net change in moisture content in the layer and the liquid water flux can be calculated with finite differences, the residual is again due to the vapor flux, this time in mass units. The time series of vapor flux calculated by the mass equation and vapor flux calculated by the energy equation were in good agreement (Cahill and Parlange, 1998). The vapor flux as predicted by Philip and de Vries underestimated the values derived from the field measurements by one order of magnitude.

The basis for Philip and de Vries (1957) is Fick's law

$$
q_{\mathrm{v}}=-D_{\mathrm{v}} \nabla \rho_{\mathrm{v}}
$$

where $q_{\mathrm{v}}$ is the mass flux of water vapor, $D_{\mathrm{v}}$ is a diffusion coefficient and $\rho_{\mathrm{v}}$ is the density of water vapor in the soil air. As discussed above in the Philip and de Vries model there are a number of extensions for soils. The most important assumption to apply (15) in soils is that convective transport of the water vapor can be neglected. The neglect of convective vapor transport for field soils is incorrect since water vapor flux may arise from a thermally-driven convective transport mechanism.

The diurnal heating of the land by the sun can lead to significant air movement in soils. The flow is due to the alternating expansion and contraction of the soil air in response to the varying soil temperature. As will be shown, the resulting convective transport of water vapor can explain the observed vapor flow (Cahill et al., 1998). is,

The transport of water vapor including convection

$$
q_{\mathrm{v}}=-D_{\mathrm{v}} \frac{\partial \rho_{\mathrm{v}}}{\partial Z}+u_{\mathrm{a}} \rho_{\mathrm{v}}
$$

where $u_{\mathrm{a}}$ is the velocity of the soil air. The soil air includes the water vapor as well as the species which make up air, so that $u_{\mathrm{a}}$ is the volume-average velocity. To derive $u_{\mathrm{a}}$ we start from the equation of continuity:

$$
\frac{\partial}{\partial t}\left(\epsilon_{\mathrm{g}} \rho_{\mathrm{a}}\right)+\frac{\partial}{\partial Z}\left(\rho_{\mathrm{a}} u_{\mathrm{a}}\right)=0
$$

where $\rho_{\mathrm{a}}$ is the soil air density, $\epsilon_{\mathrm{g}}$ is the gas phase volume fraction and $z$ is the vertical coordinate measured downwards from the soil surface. At the pressures and temperatures of interest here air behavior is close to that of a perfect gas so we use

$$
P=R_{\mathrm{a}} \rho_{\mathrm{a}} T
$$

where $R_{\mathrm{a}}$ is the gas constant for air, $P$ the pressure, and $T$ the absolute temperature. Substitution of the equation of state Eq. (18) into the continuity equation Eq. (17) and integrating from a depth below the surface where the temperature does not change with time the velocity is obtained (Whitaker, 1997; Cahill et al., 1998),

$$
u_{\mathrm{a}}=\frac{1}{\rho_{\mathrm{a}}} \int_{m=z_{0}}^{m=z}\left(\epsilon_{\mathrm{g}} \frac{\rho_{\mathrm{a}}}{T} \frac{\partial T}{\partial t}-\rho_{\mathrm{a}} \frac{\partial \epsilon_{\mathrm{g}}}{\partial t}\right) \mathrm{d} m
$$

where $\epsilon_{\mathrm{g}}$ is the volume fraction occupied by the gaseous phase, and $z_{0}$ is the depth at which $\partial T / \partial t=0$.

In Fig. 1 a comparison of the change in moisture content due to vapor flux into or out of a $7-10 \mathrm{~cm}$ layer in the Davis experimental field derived from the energy balance field observations (solid line) is presented for one day (Cahill and Parlange, 1998). In addition the change in moisture content due to vapor flux obtained with the Philip and de Vries diffusion formulation (short dashed) and the change due to the diffusion and convective transport (long dashed) are presented (Cahill et al., 1998). Notice the reasonable comparison of this new theoretical formulation for convective (plus diffusion) transport and the contribution to the change in moisture content from water vapor flux derived from the measurements. Note the strong underestimation with the diffusion approach of Philip and de Vries. For greater confidence in this approach we consider another location in the same field for a $2-4 \mathrm{~cm}$ layer (see Fig. 2). It is clear from Figs. 1 and 2 that the diffusive flux accounts for a small part of the total vapor flux while the convective flux accounts for most of the actual water vapor movement. 


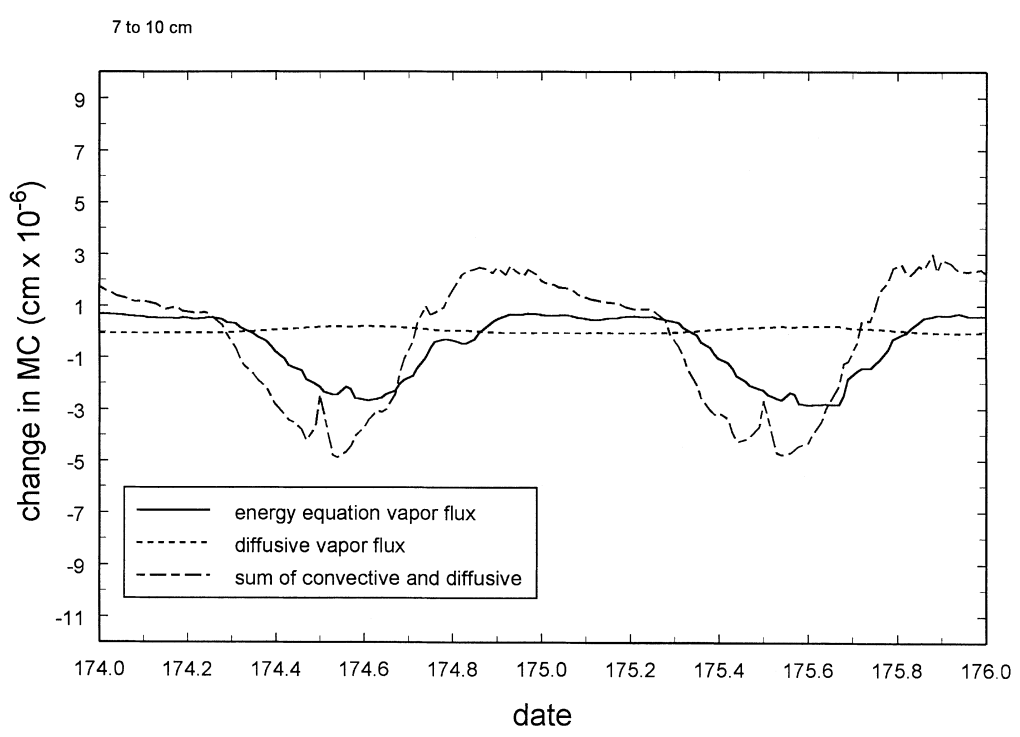

Fig. 1. Change in moisture content for two days due to water vapor transport for the 7-10 cm soil layer as derived from the soil measurements and the energy balance (solid line); the proposed convective plus diffusive transport model (variable dashed line); and the pure diffusive theory (dashed line). Note the close match in the change in moisture content with time for the new theory (diffusive+convective) and the vapor flux contribution derived from the observations.

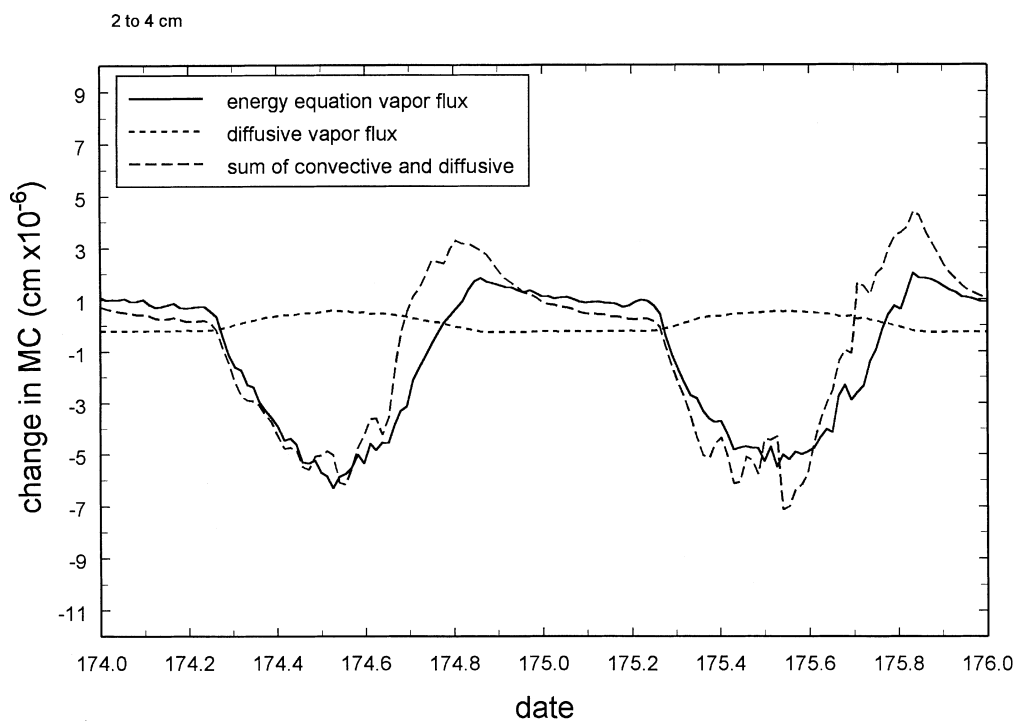

Fig. 2. Change in moisture content for two days due to water vapor transport for an additional location in the field at the Campbell Tract for a 2-4 cm soil layer. Note the satisfactory comparison of the vapor flux contribution to moisture content change derived from field observations and the new theory.

\section{Conclusions}

We have demonstrated the importance of the convective water vapor flux to the mass and energy balances in a diurnally-heated field soil near the land-atmosphere interface. This convective flux arises from the expansion and contraction of the soil air as it heats and cools over the course of the day. The 
diffusive flux predicted by the classical theory of Philip and de Vries (1957) significantly underestimated the total vapor flux; while the sum of the diffusive flux and the convective flux yielded a much better match with the water vapor flux obtained from the field observations. Further measurements of coupled heat and moisture transport in diurnallyheated soils are needed. Since the soil temperature and moisture content near the land atmosphere interface are fundamental variables for agriculture applications, this discovery is basic for future advances in the management of agricultural ecosystems.

\section{Acknowledgements}

We thank our colleagues, A. Prosperetti and S. Whitaker, who have helped us to understand the convective transfer mechanism. We gratefully acknowledge funding from the USDA and Superfund grant 5P42ES0469907.

\section{References}

Boucoyous, G.T., 1915. Effect of temperature on the movement of water vapor and capillary moisture in soils. J. Agr. Res. 5, 141172.

Cahill, A.T., Parlange, M.B., 1998. On water vapor transport in field soils. Water Resour. Res. 34, 731-739.

Cahill, A.T., Parlange, M.B., Prosperetti, A., Whitaker, S., 1998. Convectively enhanced water vapor movement at the earth's surface. Water Resour. Res., (submitted).

Cary, J.W., 1979. Soil heat transducers and water vapor flow. Soil Sci. Soc. Am. J. 43, 835-839.

Cass, A., Campbell, G.S., Jones, T.L., 1984. Enhancement of thermal water vapor diffusion in soil. Soil Sci. Soc. Am. J. 48, $25-32$.

Dasberg, S., Hopmans, J.W., 1992. Time domain reflectometry calibration for uniformly and nonuniformly wetted sandy and clayey loam soils. Soil Sci. Soc. Am. J. 56, 1341-1345.

de Vries, D.A., 1958. Simultaneous transfer of heat and moisture in porous media. Trans. Am. Geophys. Union 39, 909-916.

de Vries, D.A., 1963. Thermal properties of soils. In: van Wijk, W.R. (Ed.), Physics of Plant Environment. North-Holland, Amsterdam, pp. 210-235.

Edlefsen, N.E., Anderson, A.B.C., 1943. The thermodynamics of soil moisture. Hilgardia 16, 31-298.
Fuentes, C., Haverkamp, R., Parlange, J.-Y., 1992. Parameter constraints on closed-form soilwater relationships. J. Hydrol. 134, 117-142.

Heimovaara, T.J., 1993. Design of triple-wire time domain reflectometry probes in practice and theory. Soil Sci. Soc. Am. J. 57, 1410-1417.

Hopmans, J.W., Dane, J.H., 1986. Temperature dependence of soil hydraulic properties. Soil Sci. Soc. Am. J. 50, 4-9.

Jackson, R.D., 1973. Diurnal changes in soil water content during drying. In: Bruce, R.R. et al. (Eds.), Field Soil Water Regime. Special Pub. 5, Soil Sci. Soc. Am. Proc., pp. 37-55.

Jackson, R.D., Reginato, R.J., Kimball, B.A., Nakayama, F.S., 1974. Diurnal soil-water evaporation: comparison of measured and calculated soil-water fluxes. Soil Sci. Soc. Am. J. 38, 861866.

Jury, W.A., Letey, J., , Jr.1979. Water vapor movement in soil: Reconciliation of theory and experiment. Soil Sci. Soc. Am. J. 43, 823-827.

Milly, P.C.D., 1982. Moisture and heat transport in hysteretic, inhomogeneous porous media: a matric head-based formulation and a numerical model. Water Resour. Res. 18, 489-498.

Monji, N., Hamotani, K., Omoto, Y., 1990. Dynamic behavior of the moisture near the soil-atmosphere boundary. Bull. U. Osaka. Pref. 42, 61-69.

Nassar, I.N., Horton, R., 1992. Simultaneous transfer of heat, water, and solute in porous media: I. theoretical development. Soil Sci. Soc. Am. J. 56, 1350-1356.

Nassar, I.N., Horton, R., Globus, A.M., 1992. Simultaneous transfer of heat, water and solute in porous media: II. experiment and analysis. Soil Sci. Soc. Am. J. 56, 13571365.

Philip, J.R., de Vries, D.A., 1957. Moisture movement in porous materials under temperature gradients. Trans. Am. Geophys. Union 38, 222-232.

Rose, C.W., 1968a. Water transport in soil with a daily temperature wave I. theory and experiment. Aust. J. Soil Res. 6, 31-44.

Rose, C.W., 1968b. Water transport in soil with a daily temperature wave II. analysis. Aust. J. Soil Res. 6, 45-57.

Scanlon, B.R., Milly, P.C.D., 1994. Water and heat fluxes in desert soils 2. numerical simulations. Water Resour. Res. 30, 721733.

van Genuchten, M.Th., 1980. A closed-form equation for predicting the hydraulic conductivity of unsaturated soils. Soil Sci. Soc. Am. J. 44, 892-898.

Whitaker, S., 1997. Coupled transport in multiphase systems: a theory of drying. Adv. Heat Transfer, 31.

Westcot, D.W., Wierenga, P.J., 1974. Transfer of heat by conduction and vapor movement in a closed soil system. Soil Sci. Soc. Am. Proc. 38, 9-14.

Wierenga, P.J., Nielsen, D.R., Hagen, R.M., 1969. Thermal properties of a soil based upon field and laboratory measurements. Soil Sci. Soc. Am. Proc. 33, 354-360. 